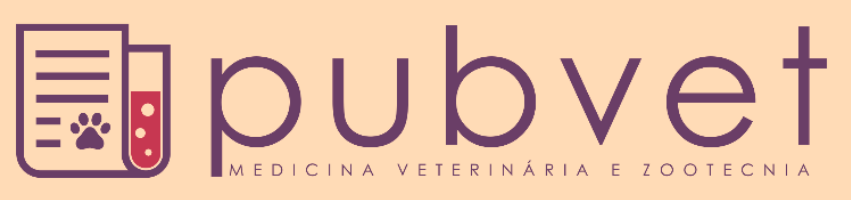

https://doi.org/10.31533/pubvet.v15n10a948.1-7

\title{
Achados necroscópicos de gota úrica visceral em lóris arco-íris (Trichoglossus haematodus): Relato de caso
}

\author{
Gabriel Almeida Moreira da Silva ${ }^{1 *}$, Thalita Michelle Queté dos $\operatorname{Reis}^{2} \bullet$ \\ ${ }^{1}$ Graduando de Medicina Veterinária da Universidade Anhembi Morumbi, campus Centro, São Paulo, São Paulo, Brasil. \\ ${ }^{2}$ Médica Veterinária Autônoma e Mestranda em Patologia Ambiental e Experimental pela Universidade Paulista, campus \\ Indianópolis/Luís Goís, São Paulo, Brasil. \\ *Autor para correspondência,E-mail: gabriel.almeida1245@outlook.com
}

Resumo. A gota úrica é um distúrbio comum em aves mantidas em cativeiro como animais de companhia, sendo caracterizada pelo depósito de cristais de urato em diversos órgãos, podendo se apresentar como gota visceral ou gota articular. Esse relato de caso trata dos achados macroscópicos de gota úrica visceral na necropsia de um lóris arco-íris (Trichoglossus haematodus). Na necropsia se destacou o acúmulo difuso de urato sobre o pericárdio, fígado, intestinos, baço e rins, não havendo sinais de gota articular. Essas lesões encontradas são condizentes com o que há descrito em literatura a respeito da gota úrica visceral. Além desses, foram encontrados também: hepatomegalia com alteração de coloração hepática podendo ser sugestivo de lipidose hepática. Sabendo que a gota é um distúrbio metabólico, existem várias possibilidades para o seu surgimento, geralmente associado a causas nutricionais como: excesso de proteínas na dieta, toxicose por Hipervitaminose D3, deficiência de vitamina A e excesso de cálcio, além de falência renal ou desidratação intensa sendo que a deficiência de vitamina A pode estar intimamente ligada a lesão renal. Hiperuricemia, um dos fatores que antecede a gota, pode estar associada ao jejum e dieta deficiente em lisina. Os fatores nutricionais são importantes ao relato de caso, uma vez que o lóris arco-íris é uma espécie com hábitos alimentares extremamente específicos, consumindo alimentos com níveis proteicos mais baixos que outras espécies de psitacídeos. Esse é o primeiro relato de gota úrica visceral em Trichoglossus haematodus.

Palavras-chave: Aves, cristais de urato, distúrbio metabólico, hiperuricemia, necropsia

\section{Necroscopic findings of visceral uric gout in rainbow loris (Trichoglossus haematodus): Case report}

\begin{abstract}
Uric gout is a common disorder in birds kept in captivity as companion animals, being characterized by the deposit of urate crystals in several organs, which can present as visceral or articular gout. This case report deals with the macroscopic findings of visceral uric gout at the necropsy of a rainbow lory (Trichoglossus haematodus). The necropsy highlighted the diffuse accumulation of urate on the pericardium, liver, intestines, spleen and kidneys, with no signs of joint gout. These lesions found are consistent with what has been described in the literature regarding visceral uric gout. In addition to these, we also found: hepatomegaly with altered liver color, which may be suggestive of hepatic lipidosis. Knowing that gout is a metabolic disorder, there are several possibilities for its onset, usually associated with nutritional causes such as: excess protein in the diet, toxicosis by hypervitaminosis D3, vitamin A deficiency and excess calcium, in addition to renal failure or severe dehydration, with vitamin A deficiency being closely linked to kidney damage. Hyperuricemia, one of the factors that precedes gout, may be associated with fasting and a
\end{abstract}


lysine-deficient diet. Nutritional factors are important in the case report, since the rainbow loris is a species with extremely specific habits, consuming foods with lower protein levels than other parrot species. This is the first report of visceral uric gout in Trichoglossus haematodus.

Keywords: Birds, urate crystals, metabolic disorder, hyperuricemia, necropsy

\section{Introdução}

A gota representa um dos distúrbios metabólicos mais comuns na clínica de aves e um dos mais importantes (Bandyopadhyay, 2017; Grespan \& Raso, 2014), podendo ocorrer de duas formas nesses animais, sendo essas, a gota articular e a gota visceral (Burgos-Rodríguez, 2010). Os animais com gota tendem a se sentir indispostos e apresentar depósitos de ácido úrico em torno das vísceras ou sob a pele das pernas e pés (Harcourt-brown, 2010).

O ácido úrico é produzido no fígado a partir da quebra de proteínas dietéticas e desaminação de aminoácidos, sendo excretado via secreção tubular, processo dependente da remoção regular por diurese que no comprometimento da função renal pode estar prejudicada levando ao acúmulo de urato dentro dos rins (Bandyopadhyay, 2017; Cojean et al., 2020). A gota ocorre quando a concentração plasmática de urato de sódio excede sua solubilidade, estimada em cerca de 600 lmol/L (nível mínimo); sendo um dos principais fatores que colaboram com a hiperuricemia a insuficiência renal. Uma vez que o ácido úrico é excretado pela secreção tubular, níveis proteicos dietéticos que excedam a necessidade do animal e a desidratação também compreendem fatores predisponentes (Lierz, 2003). De modo geral, as causas podem ser dívidas em nutricionais, infeciosas ou toxicas (Bandyopadhyay, 2017).

A gota visceral ocorre decorrente do acúmulo de ácido úrico plasmático, que resulta em depósitos de urato em vários órgãos parenquimatosos como: pericárdio, fígado, baço e nos rins. Já na gota articular, o acúmulo de urato ocorre nas capsula articular, assim como na cavidade articular, nas bainhas das articulações, nos tendões e nos tecidos adjacentes (Burgos-Rodríguez, 2010; Grespan \& Raso, 2014). Em falências renais agudas, a gota visceral pode ocorrer isoladamente (Lierz, 2003).

Esse trabalho objetiva relatar os achados necroscópicos de gota úrica visceral em lóris arco íris, associando o quadro as principais causas, sobretudo nutricionais, importantes para a espécie.

\section{Relato de caso}

Um lóris arco íris (Trichoglossus haematodus) macho foi atendido em uma clínica particular no município de São Paulo, SP, em maio de 2021. A ave tinha cerca de sete anos de idade e vivia com a atual tutora há apenas um ano. O indivíduo foi levado a clínica por apresentar uma súbita prostração após receber uma dose de $0,5 \mathrm{mg} / \mathrm{kg}$ de metoclopramida por via intramuscular, por apresentar regurgitação repentina no mesmo dia. O animal também recebeu nistatina por via oral, sob a suspeita de ter candidíase, doença que segundo Alves et al. (2017) é muito comum em aves, com sinais clínicos que incluem perda de peso, regurgitação e presença de alimentos não digeridos nas fezes. A proprietária também relatou polidipsia há pelo menos três dias.

O animal tinha contato direto com outras aves de diversas espécies de psitacídeos e Columbiformes, mas nenhum outro apresentava os mesmos sintomas. Recebia uma dieta a base de papa específica para lóris e frutas variadas, mas também consumia ração extrusada para papagaios, que servia de base alimentar para outras aves do seu convívio. Entretanto, segundo a tutora, seu histórico mais antigo da casa anterior incluía uma alimentação que também contemplava sementes, alimento inadequado para espécie pois segundo Farias (2020) o lóris, é de maneira geral, nectívoro-insentívoro-frugivoro. Ademais, o animal possuía o costume de bicar uma série de objetos, levando a suspeita de ingestão de corpo estranho. No exame físico, ficou evidente a prostração do animal, com olhos semicerrados e cabeça baixa. Em contrapartida, parâmetros de frequência respiratória, frequência cardíaca e temperatura se encontraram normais e sem ruídos na auscultação.

Levando em conta os dados de anamnese e exame físico, a principal suspeita caiu sobre uma sensibilidade ou reação a metoclopramida pois antes da aplicação da medicação o animal não apresentava sinais graves, exceto o episódio de regurgitação pontual. Massey (1993) descreve um caso 
de reação a metoclopramida em arara canindé (Ara ararauna) com sinais de ataxia, torcicolo e opistótono; com reversão dos sintomas após administração de difenidramina, um bloqueador de receptores H1 de primeira geração, com atividade anticolinérgica. Ademais, Al-Zubaidy \& Mohammad (2005) apresentam dados que sugerem que a metoclopramida induz depressão do SNC em pintos, levando a sinais de sedação caracterizados por pálpebras fechadas, inclinação da cabeça e asas, redução de motilidade e diminuição da vocalização.

O animal veio a óbito no mesmo dia que foi atendido e foi necropsiado. Na abertura da cavidade celomática, foi encontrada uma pequena quantidade de líquido livre no lado esquerdo, ademais, os achados macroscópicos incluíram uma dilatação acentuada em pro ventrículo, de coloração rosa pálido, com serosa aderida a musculatura e de difícil separação. Não foram encontrados corpos estranhos em topografia de pro ventrículo e ventrículo, que era uma das suspeitas da tutora. Além disso, foi observada esplenomegalia, sendo observado o depósito de urato na superfície do mesmo. Hepatomegalia evidente, e silhueta cardíaca globosa com perda da relação cardiohepática de ampulheta (Figura 1).

A característica mais marcante foi a deposição de cristais de urato de maneira difusa em órgãos parenquimatosos como intestinos, rins, baço, fígado e pericárdio, se destacado o acúmulo sobre os dois últimos órgão citados, sobretudo na base do coração (Figura 2).

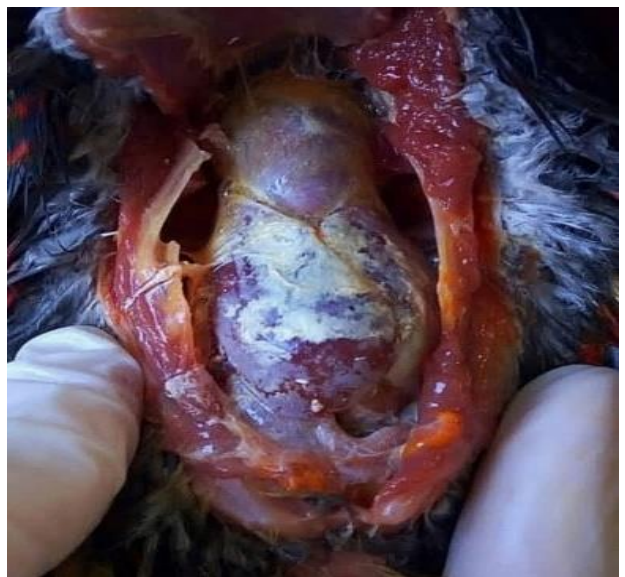

Figura 1. Alterações macroscópicas. Deposição difusa de material esbranquiçado sobre pericárdio e serosa do fígado, característica de gota úrica visceral, além de hepatomegalia e silhueta cardíaca globosa com perda de relação cardiohepática.

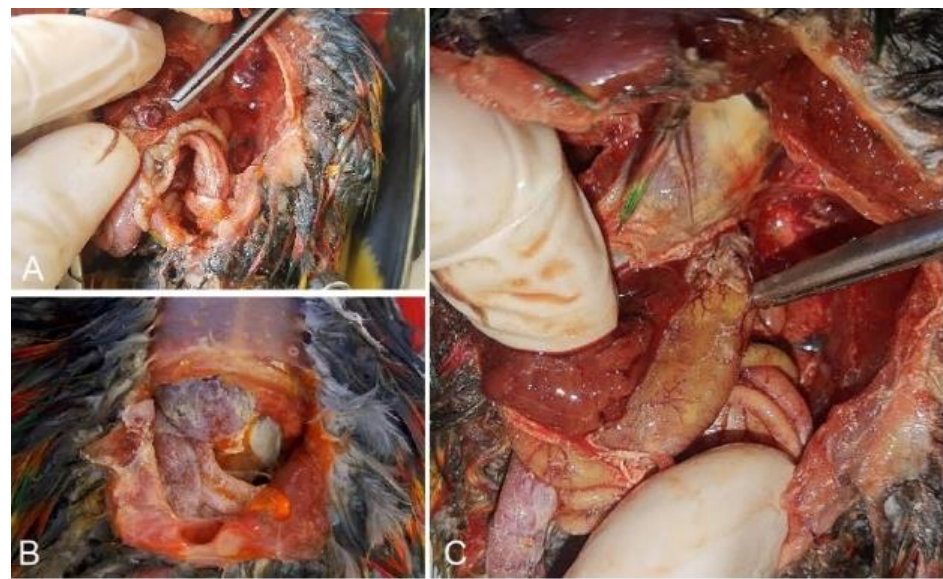

Figura 2. Esplenomegalia com deposição de urato na superfície do baço (A), assim como na superfície de outros órgãos como fígado, intestinos e ventrículo como fica evidente logo na abertura da cavidade celomática (B), além de dilatação acentuada em pro ventrículo, de coloração rosa pálido, com serosa aderida a musculatura e de difícil separação.

\section{Discussão}

As alterações macroscópicas encontradas são condizentes com o que foi relatado por outros autores sobre gota úrica visceral, que relatam deposição de cristais de urato nas serosas de diversos órgãos, sobretudo nos rins, pericárdio, fígado (Grespan \& Raso, 2014; Harcourt-brown, 2010) e baço (BurgosRodríguez, 2010; Lierz, 2003). Ademais o quadro clínico condiz com o que é descrito por Grespan \& Raso (2014) que colocam que a gota visceral, de caráter agudo, raramente é identificada em aves vivas, sendo diagnosticada somente na necropsia. Os achados desse caso foram, em parte, semelhantes aos relatados por Alvarez et al. (2015) que descreve quadro de gota úrica articular e visceral na mesma espécie. Com exceção dos sintomas de gota articular, hipotermia e dispneia, ambos os casos apresentaram sinais agudos de prostração e apatia e no exame necroscópico foi observado material esbranquiçado depositado sobre o parênquima renal, pericárdio, serosa do fígado, intestinos e ventrículo.

A gota pode ser tanto primária quanto secundária. Na gota primária há quebra anormal da proteína levando a um aumento do ácido úrico na corrente sanguínea, portanto, os rins não conseguem compensar a superprodução desses compostos metabólicos e a excreção não é mais possível levando a deposição de cristais de urato; já a gota secundária decorre do mal funcionamento do rim por doenças renais (Bandyopadhyay, 2017). Condições comumente associadas ao desenvolvimento de hiperuricemia pré renal incluem a desidratação, hipovolemia e insuficiência cardíaca congestiva (Cojean et al., 2020). O 
choque costuma ser a causa da doença renal aguda, acompanhada de anuria; já a insuficiência renal crônica pode ser causada por agentes nefrotóxicos, desidratação crônica ou obstrução ureteral (Lierz, $\underline{2003}$ ).

De acordo com Farias (2020) a gota é multifatorial, podendo estar associada a alguns fatores nutricionais como uma dieta rica em proteínas, super ingestão alimentar, toxicoses por hipervitaminose D3, deficiências de vitamina A e desequilíbrios no cálcio. Embora o excesso de proteína da dieta tenha sido associado a hiperuricemia, como coloca Bandyopadhyay (2017), dizendo que altas quantidades de proteína dietética são responsáveis por precipitar grandes níveis de ácido úrico nas aves, uma vez que quando a quantidade produzida ultrapassa a capacidade de eliminação é instalada hiperuricemia e ocorrem os depósitos de urato. Outros autores como Harrison \& Mcdonald (2006) defendem que as aves geralmente conseguem eliminar o excesso de ácido úrico, e que outros fatores são associados ao seu aumento, como jejum, desidratação e dieta deficiente em lisina.

A afirmação de que a proteína dietética desbalanceada pode ser uma indutora da hiperuricemia pode ter caráter espécie-específico. Em um estudo realizado com calopsitas (Nymphicus hollandicus) não houve evidência de gota visceral ou articular em animais alimentados com níveis de proteína total de $11 \%, 20 \%, 35 \%$ e 75\% durante 11 meses. Mesmo com acréscimo linear nos níveis de ácido úrico, houve apenas aumento significativo de lesão hepática em animais alimentados com níveis de proteína acima de $11 \%$, indicando que calopsitas são capazes de regular enzimas para o catabolismo de aminoácidos assim como os mecanismos de excreção de nitrogênio em resposta a altos níveis de proteína na dieta, sendo assim, a proteína dietética não é associada a disfunção renal nessa espécie (Koutsos et al., 2001). Em outro estudo, dietas com teor de proteína de $42,28 \%$ usadas na alimentação de frangos de corte de 18 dias durante 15 semanas induziram múltiplas alterações, dentre elas gota, sendo assim, algumas lesões renais como a gota devem ser associadas ao excesso de proteína na dieta de aves apenas em condições específicas (Cojean et al., 2020). Perdas obrigatórias de nitrogênio no processo digestivo são bastante baixas em espécies que consomem néctar em comparação com espécies granívoras, reflexo de um mecanismo que favorece a retenção de nitrogênio bastante comum em aves que consomem dietas ricas em açúcar, reforçando a necessidade proteica menor nessas espécies (Frankel \& Avram, 2001; Koutsos et al., 2001).

Segundo Koutsos et al. (2001) os lóris consomem o pólen e néctar das flores com auxílio de suas línguas extremamente especializadas, mais longas e estreitas que as de outros psitacídeos, com borda em escova que permitem alimentação e ingestão hídrica sem igual. Além disso, de acordo com os autores esses animais frequentemente se alimentam de outros itens dietéticos, incluindo frutas, sementes e insetos. Os fatores relacionados a dieta são importantes nesse relato de caso, pois apesar do animal ter acesso a uma dieta específica para lóris, convivia com alguns Amazona aestiva e frequentemente tinha acesso a sua dieta. A espécie desse relato, assim como outros Loriinis, tem uma dieta extremamente específica, sendo suas fontes alimentares naturais pobres em proteínas e consequentemente suas necessidades proteicas menores que de outras espécies, que consomem níveis proteicos mais elevados (Frankel \& Avram, 2001). Por conta da dieta consumida pelo indivíduo desse relato, além da proteína, outros nutrientes relacionados ou não com o surgimento da gota poderiam estar desbalanceados. Frankel \& Avram (2001) verificaram que as perdas de nitrogênio em lóris arco-íris são muito baixas, inclusive em comparação com outras aves frugívoras-nectarívoras, e que a necessidade proteica de manutenção gira em torno de 2,9\% com uso de proteínas da clara de ovo. Contudo, o requerimento se eleva para proteínas menos digestíveis, como as proteínas do pólen, cuja necessidade é de $8,6 \%$. Segundo os autores, isso ocorre, pois, a digestibilidade dos alimentos influencia a quantidade necessária de consumo para atender as demandas orgânicas.

Alguns fatores nutricionais podem estar diretamente associados ao surgimento de lesão renal com consequente gota secundária. Segundo Harrison \& Mcdonald (2006), os danos renais extensos associados a alteração na eliminação do ácido úrico também podem estar associados a deficiência de vitamina $\mathrm{A}$, onde os ureteres e ductos coletores renais podem sofrer metaplasia (Echols, 2006). Os lipídeos da dieta têm sido associados a progressão de doenças renais crônicas, sobretudo em relação ao equilíbrio das prostaglandinas renais por parte do ácido araquidônico presente na dieta (Harrison \& Mcdonald, 2006). Citocinas derivadas de ácidos graxos ômega-6 ligados a membrana, como o ácido araquidônico, incluem prostaglandinas, tromboxanos e leucotrienos que são substâncias pró- 
inflamatórias e vasoativas responsáveis pela progressão da doença renal crônica através da produção de radicais livres e depleção de antioxidantes (Cojean et al., 2020). Já as consequências das toxicoses por Hipervitaminose D3 incluem: calcinose visceral, nefrocalcinose, nefrose de urato e a própria gota visceral (Harrison \& Mcdonald, 2006). A Hipervitaminose D3 e/ou o cálcio excessivo muitas vezes levam a hipercalcemia e mineralização dos tecidos moles do parênquima renal (Lierz, 2003). Minerais como cálcio quando em excesso podem gerar danos aos rins, assim como as deficiências marginais de fosforo, uma vez que o fosforo é essencial para proteger os rins dos danos induzidos pelo cálcio além de atuar como acidificante urinário, evitando a formação de cristais de urato nos rins e ureteres (Bandyopadhyay, 2017).

Outras causas para o surgimento de lesão renal incluem o uso de medicamento nefrotóxicos, má perfusão sanguínea, pouca atividade física, desidratação, estresse (Bandyopadhyay, 2017), neoplasias renais (Nobrega et al., 2020) e amiloidose (Lierz, 2003). Nos casos de desidratação, há diminuição do fluxo da urina levando ao depósito dos cristais dentro dos túbulos com reações inflamatórias graves e nefrite. Caso a desidratação seja transitória há possibilidade de reversão, caso não, pode levar a insuficiência renal com consequente diminuição da eliminação e hiperuricemia causando precipitação e levar a gota (Bandyopadhyay, 2017; Burgos-Rodríguez, 2010). Sendo que para Lierz (2003) a gota é mais um sinal de falência renal do que uma doença distinta, e também, na insuficiência renal aguda a gota visceral pode ocorrer isoladamente, como no caso descrito. Como o animal apresentava polidipsia, poderia haver um começo de desidratação mesmo sem evidências de desidratação no exame físico.

Embora não tão comuns, as causas infecciosas de lesão renal não devem ser deixadas de lado. Doenças infecciosas como criptosporidiose, bronquite infecciosa nefropatogênica, astrovírus de frango, vírus da nefrite aviaria e adenovírus aviário podem resultar em lesões renais (Nobrega et al., 2020). Alguns desses, como o vírus da nefrite aviária e as cepas nefropatogênicas do vírus da bronquite infecciosa, podem atuar causando danos primários aos rins pela deposição de complexo de antígenoanticorpos no glomérulo. Além disso, de acordo com os autores a infecção por poliomavírus em psitacídeos também pode causar lesões renais com consequente gota e o envolvimento da $\mathrm{E}$. coli patogênica aviária também não pode ser negada (Bandyopadhyay, 2017). Um estudo retrospectivo constatou que de 22 aves com deposição de urato caracterizada como gota visceral, 19 apresentaram nefrite tubulointersticial. Casos de infecção por Mycobacterium foram raros, afetando aves isoladas de uma variedade de táxons, várias das quais apresentavam gota ou amiloidose concomitantes, reafirmando que nessa doença as lesões primárias em fígado e pulmão podem se disseminar para outros órgãos (Nemeth et al., 2016).

Chamou atenção que além dos depósitos de ácido úrico, o fígado apresentava hepatomegalia evidente com alteração de coloração hepática, achado indicativo de esteatose hepática, que segundo Farias (2020) trata-se da deposição e armazenamento excessivo de gordura no fígado por inúmeros fatores, dentre eles, dieta rica em gordura. O néctar, alimento rico em açúcar, fornece a principal fonte de energia para lóris e outras espécies nectarívoras (Koutsos et al., 2016), diferentemente de outras espécies, onde os lipídeos são mais necessários como fonte de energia (Farias, 2020). Entretanto, não foi possível confirmar a presença de doença hepática pois não foram coletadas amostras para verificação das provas de lesão, função, níveis de triglicerídeos, nem foi realizado exame histopatológico do órgão.

Infelizmente não foi possível realizar o exame histopatológico, mas os achados descritos por Alvarez et al. (2015) em lóris arco-íris incluem mineralização e cristais de ácido úrico em áreas difusas do parênquima renal, serosa do fígado e entre pericárdio e epicárdio. Outros achados foram descritos em outras espécies de aves. Sales et al. (2015) descrevem como achados em gota úrica visceral em Tyto alba a presença de um delgado depósito de fibrina em tecido cárdico e infiltrado inflamatório caracterizando pericardite fibrinosa. Além disso, perihepatite necrosante, representada por degeneração e necrose periférica sub-capsular, infiltrado inflamatório com predominância de células mononucleares e ainda um leve edema no fígado. Por fim, congestão pulmonar difusa e infiltrado inflamatório heterofílico focal no parênquima renal. Já os achados em aves marinhas costeiras e oceânicas, descritos por Nobrega et al. (2020) incluem estruturas multifocais fracamente eosinofílicas e radiantes, substituindo o parênquima renal circundado por necrose e infiltrado histiocítico, caracterizando tofo gotoso, esses se encontraram predominantes nos rins, mas também foram observados em fígado, baço, pulmão, epicárdio. 
Como o acúmulo de cristais de urato prejudica o funcionamento de órgãos-chave (Harrison; McDonald, 2006) surgiu a hipótese de que o animal já estava em estado crítico avançado quando recebeu a dose de metoclopramida. Segundo a bula desse medicamento, a metoclopramida sofre metabolismo hepático de conjugação simples, sendo seu metabolismo hepático insignificante e seu uso seguro para pacientes (humanos) com doença hepática avançada, mas com função renal preservada. No presente caso, provavelmente tanto a função renal, quando a hepática estava prejudicada. Também vale lembrar que pode haver caráter-espécie específico.

\section{Conclusão}

Os achados macroscópicos em Lóris arco-íris são compatíveis com acúmulo de ácido úrico nas serosas de diversas vísceras, permitindo concluir que o animal sofria de um quadro de gota úrica visceral, sem indícios de gota úrica articular. São necessários mais estudos para verificar os efeitos da metoclopramida em aves com problemas renais ou hepáticos. Durante o levantamento bibliográfico, constatou-se que esse é um dos primeiros relatos de gota em lóris arco-íris (Trichoglossus haematodus) e o primeiro caso relatado de forma mais detalhada somente na forma visceral, sem acometimento articular.

\section{Agradecimentos}

O presente trabalho foi realizado com apoio da Coordenação de Aperfeiçoamento de Pessoal de Nível Superior - Brasil (CAPES) - Código de Financiamento 001.

\section{Referências bibliográficas}

Alvarez, M.C.; Perles, L.; Sanches, T.F.; Oliveira, J.P.; Kawanami, A.E.; Lemos, G.G.; Werther, K. Gota úrica visceral e articular em lóris arco-íris (Trichoglossus haematodus) - relato de caso. In: $39^{\circ}$ Congresso da Sociedade de Zoológicos e Aquários do Brasil. 2015. Anais $39^{\circ}$ Congresso da Sociedade de Zoológicos e Aquários do Brasil. Foz do Iguaçu: AZAB, 2015.

Al-Zubaidy, M. H. I., \& Mohammad, F. K. (2005). Metoclopramide-induced central nervous system depression in the chicken. BMC Veterinary Research, 1(1), 1-4.

Alves, J. N., Elston, L. B., \& Brisola, M. L. (2017). Incidência de Candida spp. segundo a sazonalidade em excretas de aves silvestres e exóticas cativas analisadas no Laboratório ADN/Poços de CaldasMG, Brasil (2010-2014). Pesquisa Veterinária Brasileira, 37, 1153-1158.

Bandyopadhyay, S. (2017). Systemic clinical and metabolic diseases. In B. SS (Ed.), Pet bird diseases and care (pp. 167-252). Springer.

Burgos-Rodríguez, A. G. (2010). Avian renal system: clinical implications. Veterinary Clinics: Exotic Animal Practice, 13(3), 393-411.

Cojean, O., Larrat, S., \& Vergneau-Grosset, C. (2020). Clinical management of avian renal disease. Veterinary Clinics: Exotic Animal Practice, 23(1), 75-101.

Echols, M. S. (2006). Evaluating and treating the kidneys. In G. J. Harrison \& T. L. Lightfoot (Eds.), Clinical avian medicine (pp. 451-492). Spix Publishingg.

Farias, N. C. (2020). Dietas comerciais e caseiras e sua relação com os distúrbios nutricionais em psitacídeos. UniCEUB.

Frankel, T. L., \& Avram, D. (2001). Protein requirements of rainbow lorikeets, Trichoglossus haematodus. Australian Journal of Zoology, 49(4), 425-443.

Grespan, A., \& Raso, T. F. (2014). Psittaciformes (Araras, Papagaios, Periquitos, Calopsitas e Cacatuas). In Z. S. Cubas, L. C. R. Silva, \& J. L. Catão-Dias (Eds.), Tratado de animais selvagens: Medicina Veterinária (pp. 550-589). Roca, Brasil.

Harcourt-brown, N. H. (2010). Aves Psitaciformes. In T. N. Tully Junior, G. M. Dorrestein, \& A. K. Jones (Eds.), Clínica de Aves (pp. 122-149). Elsevier Brasil.

Harrison, G. J., \& Mcdonald, E. D. (2006). Nutritional considerations: Nutritional disorders. In G. J. Harrison \& T. L. Lightfoot (Eds.), Clinical avian medicine (Spix Publi, p. 131 p.).

Koutsos, E. A., Matson, K. D., \& Klasing, K. C. (2001). Nutrition of birds in the order Psittaciformes: 
a review. Journal of Avian Medicine and Surgery, 15(4), 257-275.

Koutsos, E., Gelis, S., \& Echols, M. S. (2016). Advancements in nutrition and nutritional therapy. In B. L. Speer (Ed.), Current Therapy in Avian Medicine and Surgery (pp. 142-176). Elsevier.

Lierz, M. (2003). Avian renal disease: pathogenesis, diagnosis, and therapy. The Veterinary Clinics of North America. Exotic Animal Practice, 6(1), 29-55.

Massey, J. G. (1993). Adverse drug reaction to metoclopramide hydrochloride in a macaw with proventricular dilatation syndrome. Journal of the American Veterinary Medical Association, 203(4), $542-544$.

Nemeth, N. M., Gonzalez-Astudillo, V., Oesterle, P. T., \& Howerth, E. W. (2016). A 5-year retrospective review of avian diseases diagnosed at the Department of Pathology, University of Georgia. Journal of Comparative Pathology, 155(2-3), 105-120.

Nobrega, D. F., Domiciano, I. G., Domit, C., \& Bracarense, A. P. F. R. L. (2020). Visceral gout in coastal and oceanic seabirds in Paraná, southern of Brazil. Acta Scientiae Veterinariae, 48(Supl.), 480. https://doi.org/10.22456/1679-9216.98490.

Sales, I. S., Nogueira, C. H. O., \& Silveira, L. S. (2015). Gota úrica visceral em coruja suindara (Tyto alba) de vida livre. Pesquisa Veterinária Brasileira, 35, 169-172.

Histórico do artigo:

Recebido: 29 de maio de 2021

Aprovado: 5 de julho de 2021
Licenciamento: Este artigo é publicado na modalidade Acesso Aberto sob a licença Creative Commons Atribuição 4.0 (CC-BY 4.0), a qual permite uso irrestrito, distribuição, reprodução em qualquer meio, desde que o autor e a fonte sejam devidamente creditados. 